\title{
OJS

\section{ESTÁGIO DOCENTE EM GEOGRAFIA E EDUCAÇÃO ESCOLAR INDÍGENA: EXPERIÊNCIAS NA ESCOLA INDÍGENA TATAKTI KYIKATEJÊ - ALDEIA GAVIÃO - BOM JESUS DO TOCANTINS-PA}

Dionel Barbosa Ferreira Junior' ${ }^{1}$ Igor Murilo Andrade Salame², Robson Alves dos Santos ${ }^{3}$, Marcus Vinicius Mariano de Souza ${ }^{4}$

${ }^{1}$ Graduado em Geografia pela Universidade Federal do Sul e Sudeste do Pará. E-mail: dioneljunior41@gmail.com - ORCID iD: http://orcid.org/0000-0001-8000-616X;

${ }^{2}$ Graduando em Geografia pela Universidade Federal do Sul e Sudeste do Pará. E-mail: igorsalame@gmail.com - ORCID iD: http://orcid.org/0000-0002-7452-3694;

${ }^{3}$ Professor Doutor em Geografia na Universidade Federal do Sul e Sudeste do Pará. E-mail: robson.geografia@unifesspa.edu.br-ORCID iD: http://orcid.org/0000-0003-4467-8019;

${ }^{4}$ Professor Doutor em Geografia na Universidade Federal do Sul e Sudeste do Pará. E-mail: marcussouza@unifesspa.edu.br-ORCID iD: http://orcid.org/0000-0002-4674-1539.

Artigo recebido em 17/11/2020 e aceito em 24/12/2020

\section{RESUMO}

Esta pesquisa busca explanar acerca da experiência vivida durante o Estágio Docente III, por alunos do curso de Geografia da Universidade Federal do Sul e Sudeste do Pará que ocorreu na Escola Estadual Indígena de Ensino Fundamental e Médio Tatakti Kyikatejê, localizada na Aldeia Gavião no município de Bom Jesus do Tocantins Pará. Para a elaboração deste trabalho os procedimentos metodológicos foram: a) levantamento bibliográfico, b) observação do espaço escolar e da Aldeia Gavião; c) observação das aulas de Geografia na escola e d) regência de aula. Pretende-se também entender a diferenciação da educação escolar indígena. A educação escolar fornece aos acadêmicos maneiras diferentes de se ver o mundo, respeitando e lidando com a pluralidade presente no eixo educacional, ponto esse que agrupa e junta os demais indivíduos à sociedade.

Palavras-chave: Estágio Docente em Geografia; Educação Escolar Indígena; Extensão acadêmica; Ensino de Geografia.

\section{TEACHING INTERNSHIP IN GEOGRAPHY AND INDIGENOUS SCHOOLING EDUCATION: EXPERIENCES AT THE TATAKTI KYIKATEJÊ INDIGENOUS SCHOOL - GAVIAO VILLAGE - BOM JESUS DO TOCANTINS-PA}

\begin{abstract}
This research aims to present the Geography students experience during the subject Teaching Internship III, which took place at Tatakti Kyikatejê Indigenous Elementary and High School, located in Gaviao Village in the municipality of Bom Jesus do Tocantins - Para. The methodological procedures to prepare this paper were: a) bibliographic survey; b) observation of the school space and Gaviao Village; c) examination of Geography classes at school and d) conducting classes. We also intend to understand the differentiation of indigenous schooling education. The school education provides academics with different ways of seeing the world, respecting and dealing with the plurality present in the educational axis, a point that groups and joins other individuals to society. Keywords: Teaching Internship in Geography; Indigenous School Education; Academic extension; Geography teaching.
\end{abstract}




\section{INTRODUÇÃO}

Atualmente nos deparamos em sala de aula com diferentes povos, culturas e modos de pensar. Dentre eles, podemos citar a presença constante de alunos indígenas em ambientes educacionais, como escolas, colégios e universidades, principalmente nas regiões Norte e Nordeste que concentram a maior parte da população indígena em nosso país. Assim, estudar meios de proporcionar uma educação de qualidade, emancipadora, significativa para essa parcela da população se faz necessário e é tarefa que cabe ao futuro professor de Geografia que tenha conhecimentos e saiba lidar de forma correta com a presença de indígenas em sala de aula, sem desconsiderar sua realidade, seus modos de vida e sua cultura.

Com base no Projeto Pedagógico (2016) do Curso de Licenciatura em Geografia da Universidade Federal do Sul e Sudeste do Pará (UNIFESSPA), a disciplina de Estágio Docente é subdividida como prática de extensão em três momentos ao longo do curso: a) Estágio I - o primeiro contato com o espaço escolar, com foco nas turmas de ensino fundamental/anos finais ( $6^{\circ}$ ao $9^{\circ}$ ano); b) Estágio II - em instituições escolares de ensino médio; e, por fim, c) Estagio III - foco em instituições escolares ou não-escolares da educação inclusiva, como exemplo, escolas indígenas e na zona rural.

O estágio permite aos graduandos o contato e várias maneiras de se aproximarem da realidade social, o que se caracteriza como um processo de extensão, de ensino-aprendizagem, uma vez que é uma troca de experiências mútuas entre os sujeitos, aqui no caso o indígena, que compõem o âmbito escola-universidade. O estágio surge como intermédio da extensão universitária e sociedade e pode, assim, correlacionar as discussões teóricas do meio acadêmico com as práxis vivenciadas nos espaços educacionais. A relação entre teoria e prática permite refletir a respeito do papel das instituições de ensino que não devem se limitar ao desenvolvimento em arcabouço teórico, mas transpor tal campo e partir para princípios práticos, o que torna ainda mais relevante realizar, por exemplo, um estágio docente em uma aldeia indígena.

Assim, o referente trabalho surgiu através da disciplina de Estágio Supervisionado III e possui como objetivo relatar acerca das experiências adquiridas no período em que o estágio foi desenvolvido na Escola Estadual Tatakti Kyikatejê Kyikatêjê Amtati. Desse modo, cabe aqui analisar a educação regular presenciada no Estágio Docente III na perspectiva do ensino inclusivo, o qual visa uma educação de qualidade para todos, abrangendo os povos tradicionais, 
como povos indígenas da Aldeia Gavião, localizada no município de Bom Jesus do Tocantins - Pará. Assim, buscou-se compreender como a Geografia é tratada no ambiente escolar indígena, analisando o contexto histórico e espacial da aldeia Gavião, com intuito de pesquisar como as tradições culturais são fortalecidas através da educação.

\section{MATERIAIS E MÉTODOS}

Para a realização desta pesquisa consideramos vários procedimentos e etapas, com base no objetivo proposto. As metodologias utilizadas foram pesquisa teórica e pesquisa de campo, que se deu por meio do estágio docente supervisionado. Na pesquisa teórica foi realizado um levantamento bibliográfico de autores que tratam do tema de Estágio Docente, no qual utilizamos Pimenta e Lima (2006), Pasini (2015), Saiki e Godoi (2015), sobre o ensino de Geografia utilizamos Cavalcanti (2013), Guimaraes e Lopes (2012), Rocha e Amoras (2006), sobre Educação Indígena utilizamos Luciano (2006), Gomes e Gomes (2003) e Pureza (2020). A pesquisa de campo se deu durante a realização do estágio supervisionado, no qual foram observadas aulas no período de 31 de março a 15 de abril, nos turnos matutino e vespertino, na Aldeia Gavião Tatakti Kykatejê com as turmas do $9^{\circ}$ ano do ensino fundamental e $3^{\circ}$ ano do ensino médio. Além das aulas observadas, realizou-se também a regência. Também foram realizadas observações na aldeia com o intuito compreender melhor a realidade em que os alunos estavam inseridos.

\section{DESENVOLVIMENTO}

\section{EDUCAÇÃO INDÍGENA E EDUCAÇÃO ESCOLAR INDÍGENA}

O Brasil é um dos maiores países do planeta em extensão territorial e em número de habitantes, o que o caracteriza como um país de muitos contrastes e diferenças de povos e culturas, e isso se deve ao seu processo de colonização. Dentre esses diversos povos existentes no Brasil, ainda é forte, principalmente no Norte e Nordeste do país, a presença de povos indígenas e é comum indígenas em sala de aula, o que faz importante conhecer e estudar como se dá o processo de aprendizagem de Geografia por eles. Assim, o objetivo é garantir que as populações indígenas tenham acesso à educação escolar de qualidade com profissionais da educação que respeitem suas características.

O Censo Escolar da Educação Básica mais recente, de 2018, verificou a existência 3.345 escolas indígenas no Brasil e que foram registradas 255.888 matrículas de estudantes nessas 
escolas que contam com 22.590 professores. Portanto, com base nesses dados podemos afirmar a existência de escolas indígenas e desmistificar a ideia de invisibilidade dessa parcela da população e reforçar a necessidade de formar professores capacitados a proporcionar uma educação escolar emancipadora e de qualidade para estes alunos, com intuito de formar para o exercício da cidadania e de uma sociedade mais justa. A Geografia e o seu ensino de forma crítica e reflexiva podem criar elementos para a desconstrução de estereótipos negativos que são atribuídos aos indígenas e a outras partes da população como negros e pessoas LGBTT, no sentido de compreender melhor as complexidades existentes no espaço geográfico.

Assim, considerando que o estágio docente ocorreu em uma escola indígena, cabe aqui uma breve discussão a respeito dessa temática, sendo necessário a princípio fazer alusão histórica do processo de educação imposta pelos portugueses como modo de soberania sobre os povos nativos que aqui viviam. $\mathrm{O}$ ato de ensinar chega através das escolas instituídas em território nacional brasileiro, por meio da primeira missão jesuítica enviada de Portugal por D. João III. Como forma de conquistar a confiança e aprender a língua nativa, a catequização surgiu como mediação para que fosse possível se aproximarem dos indígenas. Os primeiros contatos entre jesuítas e índios foram marcados por momentos ora em clima de grande hostilidade, ora de forma muito amistosa. $\mathrm{Na}$ visão dos catequizadores, alguns índios se mostravam resistentes, precisando assim serem pacificados, já que eram vistos como selvagens. Essa resistência à escravização teve como consequência conflitos sangrentos com os colonizadores ao longo de todo processo de ocupação do território brasileiro.

Em relação aos marcos legais, a Constituição de 1988 impulsionou para que houvesse mudanças significativas para os povos indígenas. Foi, assim, estabelecido segundo o Ministério da Educação (MEC) que no contexto da educação escolar, as entidades indígenas mantivessem as atividades de caráter educativo que, aos poucos, passaram a constituir uma rede de programas educacionais para as populações indígenas no Brasil. No documento do MEC (2007) é dito que:

Até o final da década de 80, no Brasil, a educação escolar para indígenas era conformada por uma perspectiva integracionista. O sentido da escolarização era bem claro: tratava-se de negar a diversidade dos índios e de suas culturas para integrá-los à sociedade envolvente, firmando as bases para a formação de um Estado Nacional.

A partir da Constituição Federal de 1988 tem-se um avanço, mesmo que pequeno, do direito à educação adequada às peculiaridades e à pluralidade cultural do país. A Lei no 9.39412 de 20 de dezembro de 1996 institui as Diretrizes e Bases da Educação Nacional (LDB) e em seus artigos 78 e 79, "Das Disposições Gerais", passa a ser dever do Estado oferecer às comunidades indígenas uma educação 
escolar bilíngue e intercultural, respeitando as práticas culturais e a língua materna desses povos como podemos ver a seguir:

\begin{abstract}
Art. 78. O Sistema de Ensino da União, com a colaboração das agências federais de fomento à cultura e de assistência aos índios, desenvolverá programas integrados de ensino e pesquisa, para oferta de educação escolar bilíngüe e intercultural aos povos indígenas, com os seguintes objetivos:

I- proporcionar aos índios, suas comunidades e povos, a recuperação de suas memórias históricas; a reafirmação de suas identidades étnicas, a valorização de suas línguas e ciências;

II- garantir aos índios, suas comunidades e povos, o acesso às informações, conhecimentos técnicos e científicos da sociedade nacional e demais sociedades indígenas e não-índias.
\end{abstract}

Art. 79. A União apoiará técnica e financeiramente os sistemas de ensino no provimento da educação intercultural às comunidades indígenas, desenvolvendo programas integrados de ensino e pesquisa.

$\S 1^{\circ}$ Os programas serão planejados com audiência das comunidades indígenas.

$\S 2^{\circ}$ Os programas a que se refere este artigo, incluídos nos Planos Nacionais de Educação, terão os seguintes objetivos:

I- fortalecer as práticas sócio-culturais e a língua materna de cada comunidade indígena;

II- manter programas de formação de pessoal especializado, destinado à educação escolar nas comunidades indígenas;

III- desenvolver currículos e programas específicos, neles incluindo os conteúdos culturais correspondentes às respectivas comunidades;

IV- elaborar e publicar sistematicamente material didático específico e diferenciado (BRASIL, 1996).

Diante do avanço da sociedade capitalista e de um mundo cada vez mais globalizado, percebe-se então o quão os modos de vidas tradicionais podem ser afetados devido a essa disseminação de quebra de culturas e padronizações sociais. Portanto, se faz necessário penar em um movimento de resgate cultural, sendo a educação um importante eixo para a resistência e manutenção de tais tradições, mostrando a relevância de se compreender a distinção acerca da concepção de educação indígena e educação escolar indígena.

Gomes e Gomes (2013) definem a educação indígena enquanto processo em que os povos têm como objetivo a valorização, sobrepondo os saberes, costumes e crenças dos indígenas, de modo que sejam repassados dos mais antigos aos mais jovens da aldeia. $\mathrm{O}$ âmbito familiar indígena engendra a interação através do convívio com os pais, avós, irmãos e demais membros da família, sejam por uso da comunicação oral ou visual, mantendo, assim, os interesses gerais da comunidade indígena. Sobre isso Luciano (2006) corrobora com os autores e afirma que: 
Os pais e avós são responsáveis por transmitir aos seus filhos ou netos, desde a mais tenra idade, a sabedoria aprendida de seus ancestrais. Assim, as crianças desde cedo vão aprendendo a assumir desafios e responsabilidades que lhes permitam inserir-se na vida social e o fazem, principalmente, por meio da observação, da experiência empírica e da auto-reflexão proporcionadas por mitos, histórias, festas, cerimônias e rituais realizados para tal fim. Os bons exemplos dos pais, dos irmãos mais velhos e dos líderes comunitários são fundamentais para o desenvolvimento do caráter, das atitudes, dos comportamentos, das virtudes e das habilidades de uma pessoa, indispensáveis para a vida individual e boa convivência social (p. 130).

Pureza (2020, p. 243) define a educação escolar como “[...] concepção de escola é aquela que propõe uma educação escolar voltada para a inter-relação entre os conhecimentos e formas de aprendizagens tradicionais dos povos indígenas e o conhecimento denominado "universal". O que se evidenciou foi a necessidade de aprender sobre os conteúdos "gerais", os mesmos discutidos com enfoques em processos seletivos como Enem e outras provas. A princípio havia uma certa desconfiança com relação a esse tipo de educação, pois, imaginavase que seria uma maneira de aculturação, ou seja, apropriação de cultura indígena. Santos e Faria (2016, p. 5) definem educação escolar indígena como:

Modelo de educação escolar assumida pelos próprios indígenas, com espaços e estruturas físicas apropriadas, com educadores e professores conhecedores de sua cultura, falantes da língua do seu povo da comunidade para melhor repassar aos alunos indígenas os conhecimentos tradicionais da própria cultura, é o espaço onde todos buscam construir uma nova política educacional, ao mesmo tempo aprendem os conhecimentos dos não indígenas junto com os conhecimentos tradicionais.

Assim, o que se propõe é uma Educação Escolar Indígena específica, que tenha como base a construção social, religiosa, étnica, política e cultural no sentido de construção de um modelo educacional que leve em consideração a realidade de cada grupo e que contribua efetivamente para a formação da cidadania juntamente às características próprias do seu grupo.

\section{ESTÁGIO E PERCEPÇÕES DO ESPAÇO ESCOLAR INDÍGENA NO ENSINO DE GEOGRAFIA}

A grosso modo, entende-se o estágio como o momento em que as teorias aprendidas pelos acadêmicos são aliadas à prática e efetivadas no futuro ambiente de trabalho. No caso da formação do professor, essa efetivação se dá em um ambiente escolar, e no caso aqui tratado, em uma escola indígena. Assim, o Estágio Supervisionado III ocorreu de forma concentrada em período integral de 31 de março a 15 de abril de 2019, nos turnos matutino e vespertino na 
Escola Indígena de Ensino Fundamental e Médio Tatakti Kyikatejê, localizada na Aldeia Gavião às margens da BR 222, dentro da reserva indígena Mãe Maria, no município de Bom Jesus do Tocantins no Estado do Pará. Abaixo, é possível observar a localização da escola dentro da aldeia indígena.

Figura 1- Mapa de localização da aldeia e escola indígena

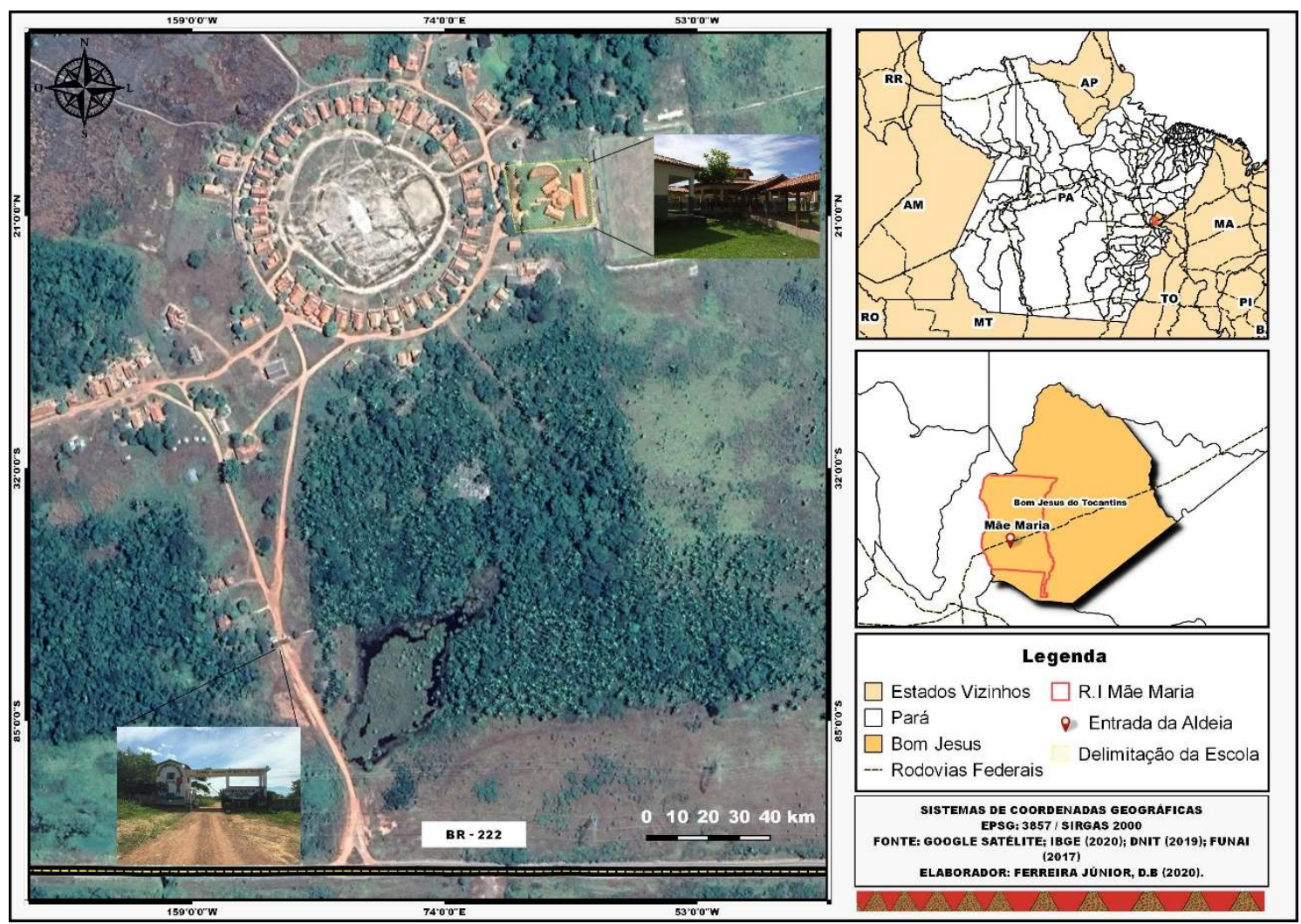

Fonte: Elaboração de Dionel Barbosa Ferreira Junior (2020).

Assim, o Estágio Supervisionado III teve como objetivo compreender como a Geografia é tratada no ambiente escolar indígena. Analisado o contexto histórico e espacial com intuito de pesquisar como as tradições culturais são fortalecidas através da educação geográfica na Aldeia Gavião Kyikatêjê.

O estágio supervisionado permite ao futuro professor conhecer, analisar e refletir sobre seu ambiente de trabalho e segundo Souza (2013, p. 108) é:

[...] atividade importante para a formação do professor de Geografia e considera-se que ele é o momento em que são criadas as condições que possibilitam ao estagiário o contato com as práticas profissionais docentes em locais onde estejam estruturadas as condições para o exercício da profissão. A escola é essencialmente um desses locais. 
Saiki $(2015$, p. 27) afirma que a disciplina de estágio "deve ser considerada como uma instrumentalização fundamental no processo de formação profissional de professores", diante disso presencia-se, então, a importância que os estágios possuem, ao proporcionarem aos discentes dos cursos de licenciatura a aproximação e interação com os sujeitos e no âmbito escolar.

É através de práticas extensionistas como o estágio docente que as práticas e teorias são evidenciadas no cotidiano, permitindo aos futuros profissionais o desenvolvimento e formas de interagir com os alunos, dando ênfase a um ensino prazeroso que se desprenda das raízes de uma educação bancária. Formando, assim, profissionais dispostos a não somente passar conhecimento, mas tornar o aluno um ser pensante, reflexivo e crítico a respeito do espaço em que convive.

Cabe ressaltar a grande importância das universidades como base da produção científica, tendo como função a prestação de um retorno social à população externa. É por intermédio das instituições educacionais que os saberes populares podem ser prospectivos e valorizados, auxiliando na resolução de problemáticas e no fomento à pesquisa, conforme pensa Gurgel (1986) quando menciona que

a extensão deve ser vista como um espaço possibilitador de estabelecimento de uma ligação com a classe trabalhadora, que permita um intercâmbio de conhecimentos, no qual a universidade aprenda a partir do saber popular e assessore as populações no sentido de sua emancipação crítica (p. 176).

Assim, o estágio foi dividido em dois momentos, as observações que foram feitas na aldeia e dentro de sala de aula e a parte da regência como veremos a seguir.

\section{OBSERVAÇÕES}

A observação é um dos meios mais utilizados para se conhecer e compreender as pessoas, as coisas, os acontecimentos e as situações de um determinado ambiente. Assim, foram realizadas observações in loco na Aldeia Gavião Kyikatêjê e na Escola Estadual Indígena de Ensino Fundamental e Médio Tatakti Kyikatejê durante as aulas com as turmas do $9^{\circ}$ ano do ensino fundamental e $3^{\circ}$ ano do ensino médio.

Uma das primeiras análises realizadas durante o estágio refere-se ao ambiente escolar. Espaço esse de suma importância para o aprendizado dos alunos, uma vez que influencia no processo de pertencimento dos jovens e interação no âmbito escolar. Observou-se que questões 
contemporâneas, devido principalmente ao processo de globalização em que a sociedade moderna passa, invadem todos os espaços geográficos, de forma hegemônica, acarretando um etnocídio, ou seja, a "morte" de uma cultura e como consequência a perda da língua nativa. Entende-se por cultura indígena tudo o que é produzido, pensado e vivido pelos povos indígenas

Devido a isso, notou-se ao longo do espaço escolar um nítido esforço da escola na preservação da língua "raiz", por meio de alfabetos e brincadeiras que utilizam as letras indígenas. Também em conversa com funcionários e professores da escola, foi relatado que na escolha dessas pessoas para trabalharem na escola, é dada preferência para quem conhece a língua e os costumes indígenas, que existe uma dificuldade de aceitação dos alunos com professores "brancos". Tudo isso em prol da preservação e valorização da educação e dos costumes indígenas, como as Figuras 2 e 3 apresentam abaixo.

Figura 2 - Jogos na língua indígena

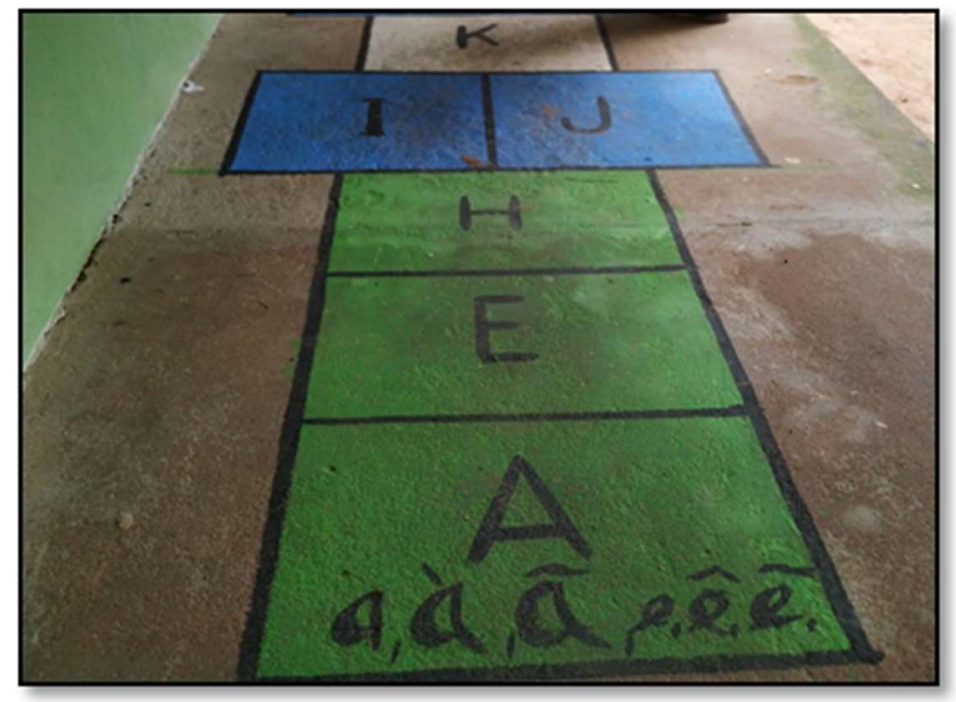

Fonte: Acervo dos autores, 2019.

Figura 3 - Representações da língua indígena ao longo da escola

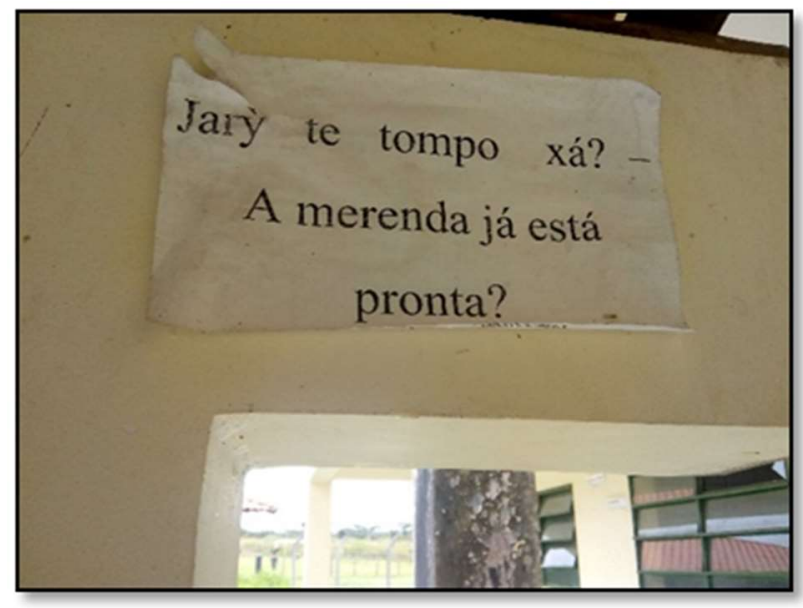

Fonte: Acervo dos autores, 2019. 
Durante as observações, a turma apesar de tímida com nossa presença em sala, no decorrer do estágio interagiu de forma positiva desenvolvendo e construindo as atividades propostas. O que é indispensável destacar são as experiências vividas nestes períodos de graduação. E o estágio serve para pormos em prática os conhecimentos adquiridos na universidade e ainda construirmos e aprendermos, a partir das experiências adquiridas no período na escola. Segundo Saiki e Godoi (2015, p. 27),

Nos estágios supervisionados colocamos as teorias em prática. Ao voltarmos à sala, nas aulas de Prática de Ensino, analisamos as experiências adquiridas à luz das teorias. O que ocorre é a articulação prática teoria prática teoria.

No período de observação foi possível fazer reconhecimento do ambiente escolar e, assim, analisar e observar a estrutura administrativa e organização do espaço. Outro ponto analisado foi que, mesmo com as dificuldades presentes na realidade da escola, a direção, professores e comunidade da aldeia buscam implementar meios que assegurem o ensino de qualidade, como a adaptação da escola para atender às necessidades e demandas dos 128 alunos referentes ao espaço da biblioteca, que mesmo com falta de investimento do Governo do Estado consegue gerir um espaço com acervo de pesquisa, disponibilizando: 47 livros de pesquisa, 400 livros de leitura, o horário de funcionamento de quinta e sexta de manhã $10 \mathrm{~h}$ às $12 \mathrm{~h}$ e tarde $14 \mathrm{~h}$ às 17:30 e professor de língua portuguesa.

Figura 4 - Biblioteca da escola indígena

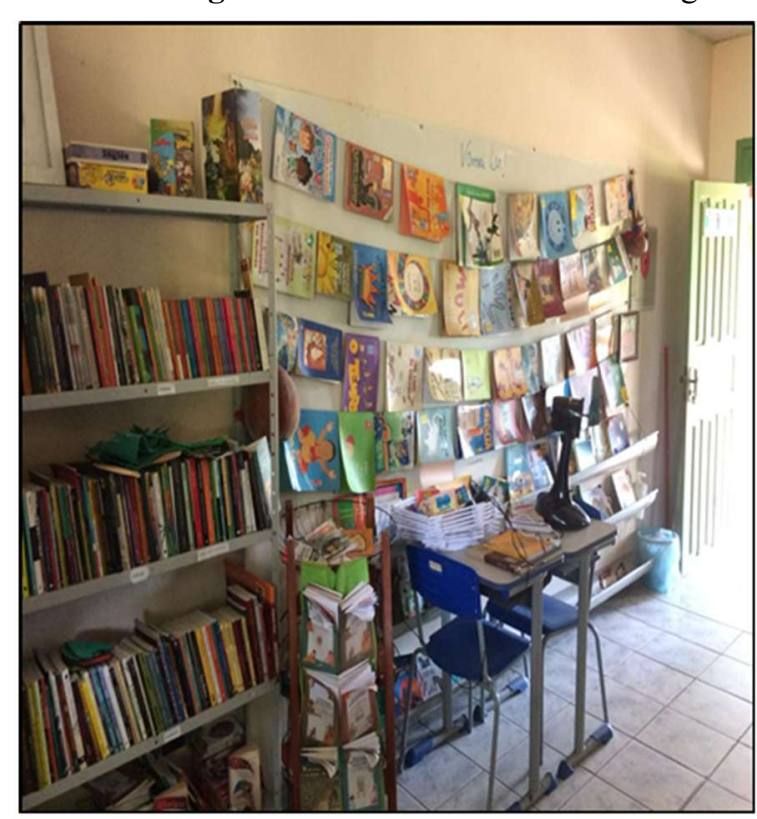

Fonte: Acervo dos autores, 2019. 
A escola dispõe de forma geral de uma boa estrutura de sala de aulas, sala dos professores, coordenação, diretoria, secretaria, refeitório, e a mobília de forma geral também está em boas condições. Em relação às aulas, pode-se observar, no que se diz respeito às práticas utilizadas pelo professor de Geografia, o uso de uma linguagem exposta de forma clara para compreensão dos alunos, onde nos conteúdos aplicados há correlação, a todo momento ocorre comparações e adequações levando em consideração o conhecimento cotidiano e cultural da aldeia dos alunos para que ocorra aprendizagem significativa.

Dentre os aspectos sociais, econômicos, religiosos, políticos, ambientais e culturais, há preocupação e uma cobrança do cacique pela busca de formação acadêmica pelos índios, para que fortaleça a luta pela defesa dos direitos dos indígenas, pois, assim como o professor da escola indígena menciona que "o índio não quer ganhar e reivindicar seus direitos à base da flecha mas, sim, do diálogo, através do conhecimento universal adquirido durante sua formação acadêmica". Dentro dessa luta pela permanência e cultura pode se notar os aspectos no ambiente da aldeia, da busca pela preservação da língua e das crenças do povo indígena e presença religiosa de uma cultura externa à aldeia.

\section{DOCÊNCIA EM GEOGRAFIA NA PRÁTICA}

Durante a experiência em sala de aula, notou-se adversidades no aprendizado para com os alunos da escola indígena, visto a baixa interação e oralidade quando solicitados, tanto com os docentes de Geografia quanto com o professor regente. As particularidades de vivência na aldeia se inserem no âmbito educacional, diferenciando-se do processo de aprendizagem realizado nas cidades, marcado por um ritmo acelerado em escolas ditas não diferenciadas.

O período de regência ocorreu na turma do $9^{\circ}$ ano do ensino fundamental, sendo necessário a construção de uma proposta de aula estruturada por meio do plano de aula, onde o conteúdo trabalhado foi pensado de acordo com a realidade da escola e dos alunos, para que de fato ocorresse aprendizado de maneira prazerosa. A aula teve como tema abordado "a cidade e suas representações", tendo como objetivo desenvolver junto aos adolescentes o conceito de cidade a partir das relações de vivência desses alunos, utilizando do conhecimento prévio de cada um.

O tema abordado na aula foi proposto com base na disciplina optativa "Ensino de Geografia e Cidade", que os discentes do curso de Geografia estavam cursando, facilitando assim na explanação do conteúdo. Para Cavalcanti (201, p. 74), “a cidade é educadora: ela educa, ela forma valores, comportamentos, ela informa com sua espacialidade, com seus sinais, 
com suas imagens, com sua escrita. Ela também é um conteúdo a ser apreendido por seus habitantes". Para Mota (2000), as cidades são a "floresta do índio", pois, estes possuem uma relação intrínseca com o espaço urbano, se tornando cada vez mais importantes, uma vez que as condições atuais de vida nas áreas indígenas criam uma dependência crescente, em prol de saúde, educação e os demais bens de serviços que devem ser oferecidos de maneira digna a toda sociedade.

Portanto, o professor torna-se um agente essencial dessa formação educacional, ocasionando maior responsabilidade para esses sujeitos, que têm a preocupação de se atualizarem - e conseguem usufruir de didáticas de ensino para poderem transpor o seu conhecimento da sua Geografia Acadêmica para sala de aula, sabendo trabalhar conceitos e conteúdos que vão além do livro didático. Conforme Moreira, Silva e Ferreira (2015, p. 73), "a sala de aula deve ser um espaço de construção e de troca de conhecimentos onde se ensina e se aprende".

As referências utilizadas para a elaboração da proposta da atividade prática com os alunos foram pautadas em artigos como "Trilhas urbanas: a cidade e o ensino de geografia", de Guimarães e Lopes (2012) e "O ensino de geografia e a construção de representações sociais sobre a Amazônia", de Rocha e Amoras (2006) - onde os alunos representaram sua compreensão sobre cidade em forma de desenho e texto, em primeiro momento, e, posteriormente, a demarcação de pontos de vivência dos alunos na cidade.

Figura 5 - Elaboração dos desenhos e texto

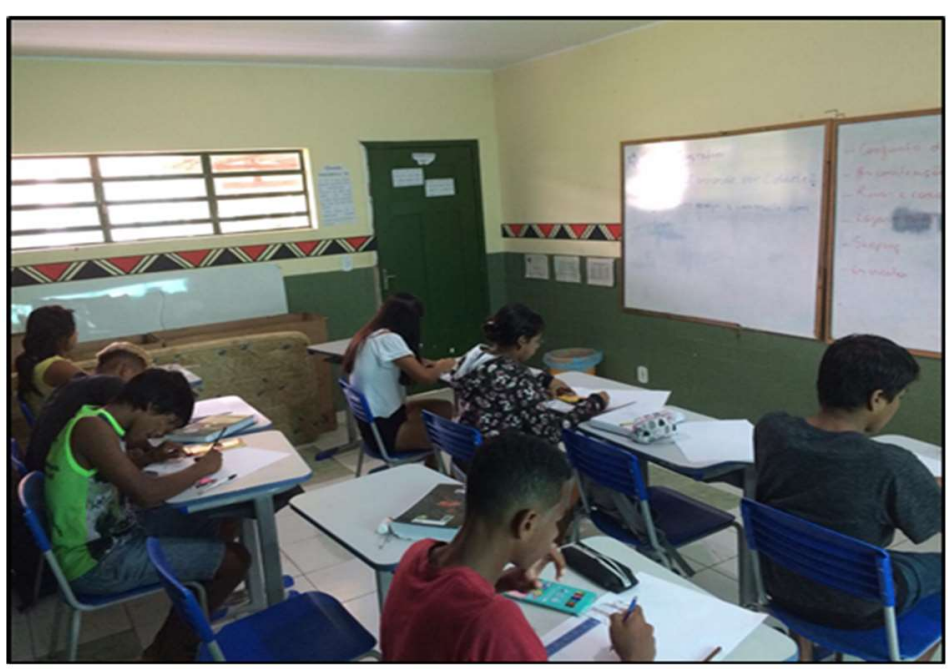

Fonte: Acervo dos autores, 2019.

Figura 6 - Localização dos lugares de consumo dos alunos 


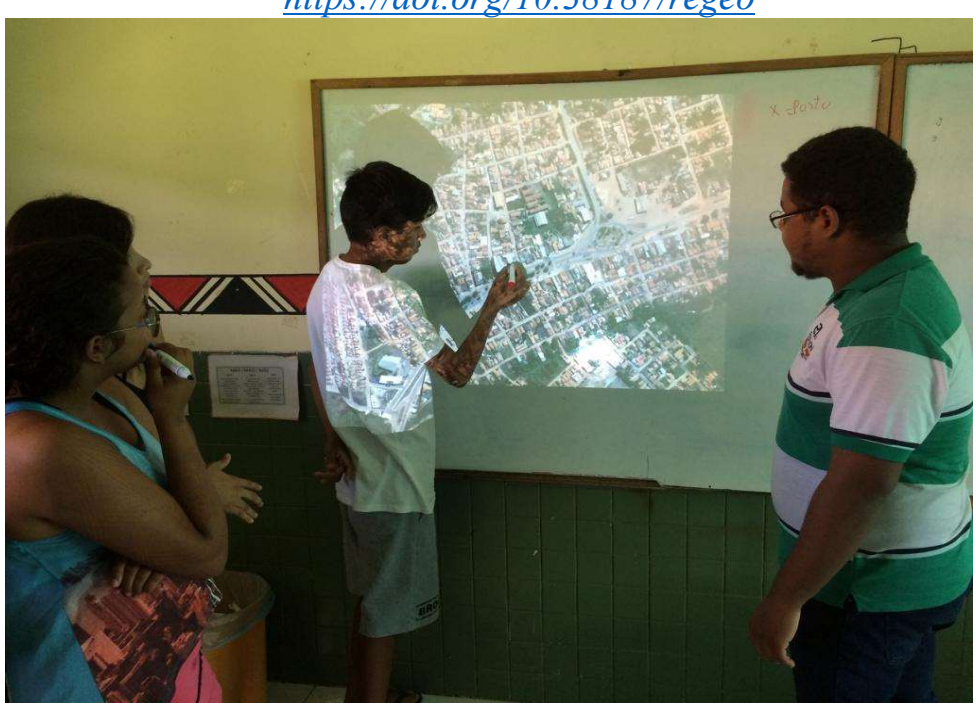

Fonte: Acervo dos autores, 2019.

A primeira atividade prática abordada com os alunos foi desenho, em que não houve intervenção por parte dos professores sobre o conceito de cidade, pois, o intuito dos desenhos é que os alunos retratem sua própria compreensão de cidade. A partir desse momento, foi planejado o slide como material para aula, na qual inserimos os desenhos, apresentamos e discutimos as representações de cidade, segundo o olhar dos alunos.

Os povos indígenas fazem o uso das pinturas/desenhos como maneira de carregar consigo seus valores e suas tradições, o que os diferencia dos homens brancos, sendo uma das formas de representação não somente em seus corpos, mas em desenhos espalhados ao longo da aldeia indígena. Para Paganelli (2009), os desenhos se tornam um "elemento de análise sobre o desenvolvimento cognitivo de certa realidade representada pelo aluno". Dessa maneira, visto a boa relação dos alunos com tal didática, foi proposta a elaboração de desenhos e em seguida discussões desses em sala, apresentando o que foi abordado a respeito da construção do conceito de cidade. Discutiu-se em seguida a origem das primeiras cidades, desde a antiguidade à cidade capitalista, advinda da revolução industrial, e por fim buscou-se repensar com os alunos a percepção associada restritamente aquilo que é belo, mostrando a eles as problemáticas que ocorrem na cidade. 
Figura 7 - Representação do Shopping Center

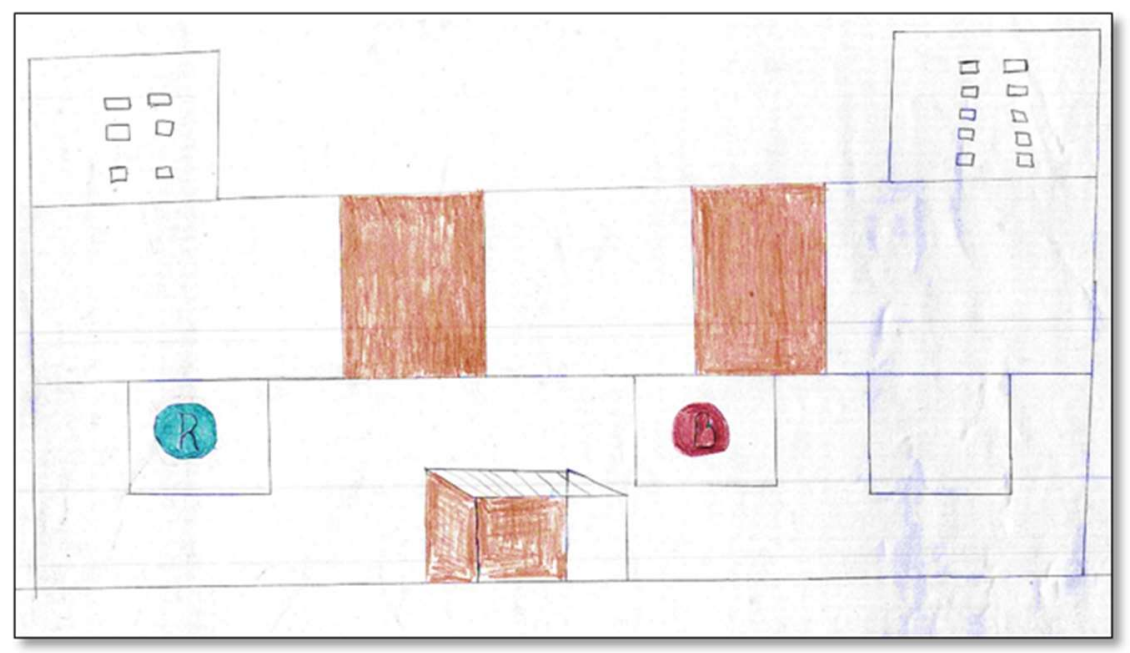

Fonte: Aluna indígena do $9^{\circ}$ ano, 2019.

Salgueiro (2006) compreende a cidade enquanto "suporte às ações desenvolvidas pelos atores", palco das relações também comerciais, visto que é cada vez maior a busca pelo consumo, seja ele em produtos ou dos espaços de lazer. O desenho acima, elaborado pela aluna indígena Jõpry de 13 anos de idade, busca representar um dos espaços de lazer/consumo: o Shopping. A aluna do $9^{\circ}$ ano destaca ainda que

O shopping é o lugar que as pessoas tiram um tempo para passear, um dos lugares que mais gosto de ir. Gosto de ir ao shopping por causa do cinema e da praça de alimentação. É o lugar onde ocorre umas apresentações e às vezes rola uns brinquedos legais (Jõpry, aluna indígena, 2019).

E como última prática proposta com os alunos para compreenderem as relações deles com a cidade, partindo do entendimento que eles são agentes ativos da produção do espaço, após demarcarem os principais locais de vivência da cidade, houve a elaboração das cartas imagem, construídas por meio do mapa colaborativo. Esse tipo de mapeamento tem o intuito de apresentar os espaços onde os sujeitos possuem relação de convívio com o lugar. A construção desse tipo de mapa permite uma participação de todos, não se limitando apenas a um elaborador. 
Figura 7 - Mapa dos lugares de consumo indicado pelos alunos

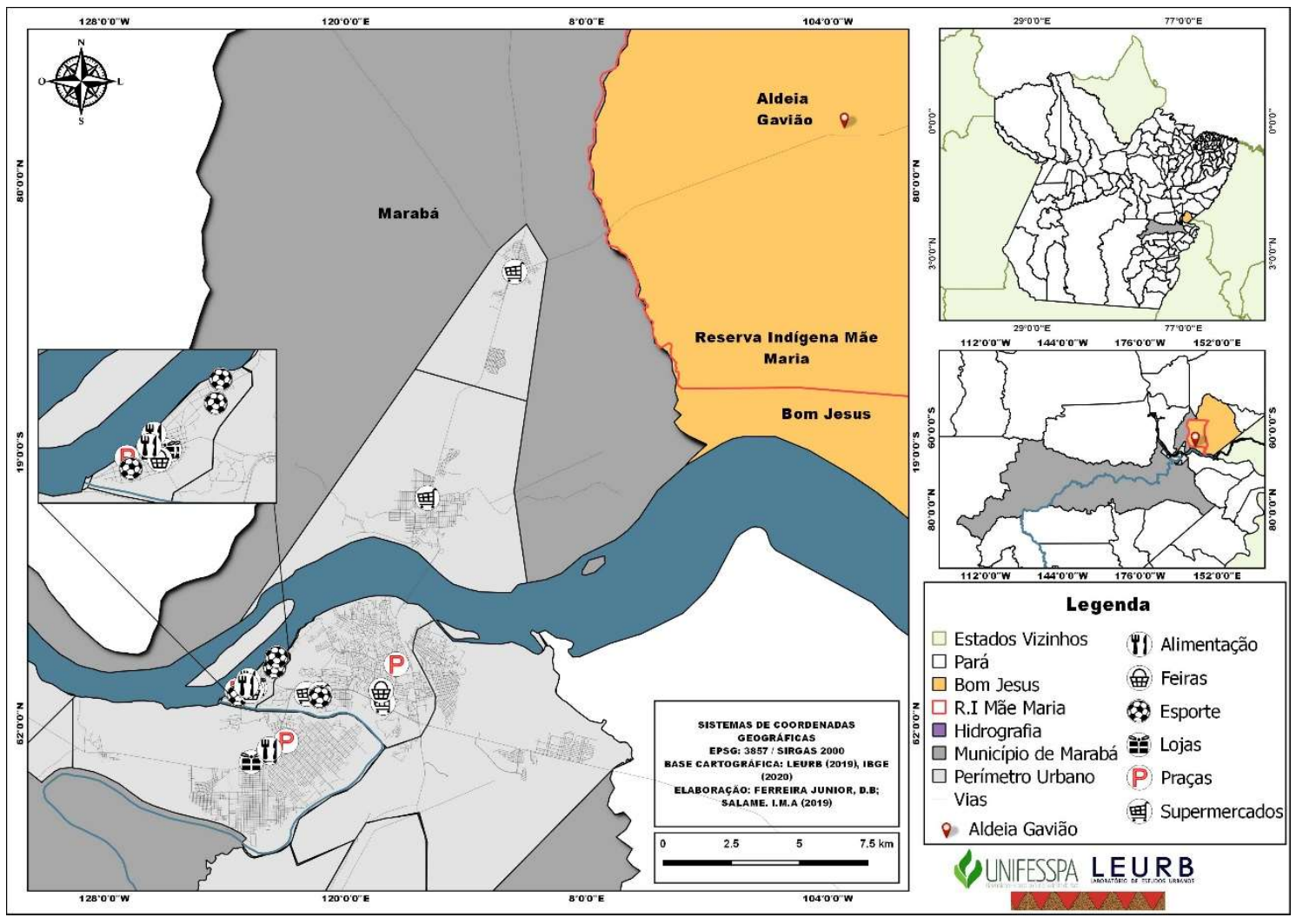

Fonte: Elaboração Dionel Barbosa Ferreira Junior e Igor Murilo Andrade Salame. (2019)

Com georreferenciamento dos pontos e elaboração das cartas imagem foi possível compreender a organização espacial dos alunos perante o consumo da cidade, a forma de consumir e as relações construídas nesses espaços de consumo e bens de serviços, práticas esportivas, ao consumo do espaço, com as praças e a orla e, assim, não somente construir os conceitos com os alunos de cidade, mais instigá-los ao papel de cidadãos agentes ativos do espaço urbano, da construção e dos movimentos da cidade. Compreendendo, então, que tais povos com suas peculiaridades fazem e convivem diariamente no âmbito urbano, sendo de suma importância dar visibilidade à diversidade de culturas presentes nos espaços citadinos.

No último momento de interação entre discentes e escola indígena houve uma espécie de debate e relatos acerca das experiências vivenciadas na universidade, com a presença de todos os estagiários, professor de Geografia da escola e coordenador do estágio III na turma do $3^{\circ}$ do ensino médio. Esses alunos já estão em processo de formação escolar, o que é de grande valorização a troca de diálogos em torno das perspectivas que os jovens indígenas possuem em relação ao futuro pós ensino básico. No decorrer da reunião, cada discente do curso de Geografia apontou os pontos positivos e das adversidades vividas na instituição superior, como maneira de sanar dúvidas para muitos jovens. 
Durante o processo de observação e diálogos com o professor indígena foi possível compreender que há uma preocupação em relação a como os alunos serão inseridos no meio acadêmico, devido às dificuldades de entendimento, sociabilidade e interação dos mesmos com outras culturas, o que corrobora para evasão dos povos indígenas do ensino superior, sendo cada vez mais necessário pensar em políticas públicas. A aldeia como um todo sente-se orgulhosa com a presença e formação dos povos indígenas no grau superior, uma vez que propicia um retorno à aldeia Gavião e uma maneira de representar seus povos em espaços de diálogos. Segundo a obra do Ministério da Educação, “o Ensino Médio é visto como uma preparação para o Ensino Superior ou para a vida profissional. Dessa forma, para o jovem indígena, representa uma passagem da vida de aldeia (indígena, tradicional) para a vida nãoindígena (cidade, emprego, dinheiro etc.)" (BRASIL, 2006, p. 161).

\section{CONSIDERAÇÕES FINAIS}

O Estágio Supervisionado em Geografia possibilitou, por meio da experiência vivida, compreender acerca da temática de inclusão dos povos indígenas, em específico o povo kyikatejê, que ao longo dos anos valoriza a inserção dos seus jovens nas instituições educacionais. O meio escolar propiciou uma série de reflexões e maneiras de se fazer a educação, de modo que os professores compreendam o meio social em que os alunos estão inseridos, ressaltando o respeito e valorização de todas as práticas culturais de seus respectivos povos.

É através de práticas extensionistas como o estágio docente que as práticas e teorias são evidenciadas no cotidiano, permitindo aos futuros profissionais o desenvolvimento e formas de interagir com os alunos, dando ênfase a um ensino prazeroso que se desprenda das raízes de uma educação bancária. Formando, assim, profissionais dispostos a não somente passar conhecimento, mas tornar o aluno um ser pensante, reflexivo e crítico a respeito do espaço em que convive.

Acredita-se que é preciso ressaltar a importância do papel da educação e do professor na sociedade, além da importância de sua qualidade, pois, ele age diretamente na esfera social, formando opiniões e propiciando o desenvolvimento crítico, reflexivo e intelectual da sociedade. Pensar um bom professor é pensar em mudanças na sua formação, o que nos faz refletir e questionar acerca de como o atual educador vem se formando, nos perguntando se este 
profissional está acompanhando as transformações da sociedade cada vez mais capitalista e desigual.

\section{REFERÊNCIAS}

BRASIL. Lei $n^{\circ} 9.394$ de 20 de dezembro de 1996. Estabelece as diretrizes e bases da educação nacional. Disponível em: www.planalto.gov.br/ccivil_03/leis/19394.htm. Acesso em: 23 de dezembro de 2020.

CAVALCANTI, L. S. A geografia escolar e cidade: Ensaios sobre o ensino de geografia para a vida urbana cotidiana. 3. ed. Campinas: Papirus, 2013.

GOMES, G. C.; GOMES, N. C. A importância da educação escolar no processo de Valorização da identidade indígena. In: XI CONGRESSO NACIONAL DE EDUCAÇÃO - EDUCERE. 2013, Paraná. Anais... Paraná: 2013.

GUIMARÃES, G. C. N.; LOPES, C. S. Trilhas urbanas: A cidade e o ensino de geografia. Cidade: Máringa, PR. Revista Geoingá, v. 4, n 2, p. 3-25, 2012.

GOULART, A. T. A importância da pesquisa e da extensão na formação do estudante universitário e no desenvolvimento de sua visão crítica. Horizonte - Revista de Estudos de Teologia e Ciências da Religião, v. 2, n. 4, p. 60-73, 2004.

INSTITUTO NACIONAL DE ESTUDOS E PESQUISAS EDUCACIONAIS ANÍSIO TEIXEIRA (INEP). Censo Escolar, 2018. Brasília: MEC, 2018.

LUCIANO, G. S. O Índio Brasileiro: o que você precisa saber sobre os povos indígenas no Brasil de hoje. Brasília: Ministério da Educação; LACED; Museu Nacional, 2006.

MOREIRA, D. S; SILVA, M. J; FERREIRA, R. J. A didática da afetividade. In: PASSINI, E.Y; PASSINI, R; MALYSZ, S.T. Práticas de ensino de geografia e estágio supervisionado. 2. ed. São Paulo: Contexto, 2015. p. 72-77.

MOTA, L. T. As cidades e os povos indígenas. Mitologias e visões. Maringá: EDUEM, 2000.

PASSINI, E. Y. Convite para inventar um novo professor. In: PASSINI, E. Y. Práticas de ensino de geografia e estágio supervisionado. 2. ed. São Paulo: Contexto, 2015. p. 32-51.

PIMENTA, S. G.; LIMA, M. S. L. Estágio e docência: diferentes concepções. Revista Poíesis, v. 3, n. 3-4, p. 5-24, 2005-2006.

PONTUSCHKA, N. N.; PAGANELLI, T. L.; CACETE, N. H. A linguagem cinematográfica no ensino de Geografia: Tecnologia, informação e conhecimento. In: Para ensinar e aprender Geografia. 3. ed. São Paulo: Cortez, 2009. p. 261-265.

PUREZA, M. G. B. O ensino de Geografia na Educação Escolar Indígena. Revista Educação e Cultura Contemporânea, v. 17, n. 48, p. 238-257, 2020.

ROCHA, G. O. R.; AMORAS, I. C. R. O ensino de geografia e a construção de representações sociais sobre a Amazônia. Cidade: São Paulo, SP. Editora: Terra livre, 2006. 
SAIKI, K.; GODOI, F. B. A prática de ensino e o estágio supervisionado. In: Práticas de ensino de geografia e estágio supervisionado. 2. ed. São Paulo: Contexto, 2015. p. 26-31.

SALGUEIRO, T. B.; CACHINHO, H. As relações cidade-comércio: dinâmicas de evolução e modelos interpretativos. Cidade: Lisboa, Portugal. Centro de estudos geográficos, 2006.

SOUZA, V. C. Desafios do estágio supervisionado na formação do professor de Geografia. In: ALBUQUERQUE, M. A. M.; FERREIRA, J. A. S. (Org.). Formação, pesquisas e práticas docentes: reformas curriculares em questão. João Pessoa: Mídia, 2013. p. 105-130. 